\title{
UCRL-TR-224299
}

LA W REN CE LIVERM ORE N A TIO NAL LABORATORY
ISO 17025 Accreditation Experience at LLNL

T. E. Mitchell-Hall

September 9, 2006 
This document was prepared as an account of work sponsored by an agency of the United States Government. Neither the United States Government nor the University of California nor any of their employees, makes any warranty, express or implied, or assumes any legal liability or responsibility for the accuracy, completeness, or usefulness of any information, apparatus, product, or process disclosed, or represents that its use would not infringe privately owned rights. Reference herein to any specific commercial product, process, or service by trade name, trademark, manufacturer, or otherwise, does not necessarily constitute or imply its endorsement, recommendation, or favoring by the United States Government or the University of California. The views and opinions of authors expressed herein do not necessarily state or reflect those of the United States Government or the University of California, and shall not be used for advertising or product endorsement purposes.

This work was performed under the auspices of the U.S. Department of Energy by University of California, Lawrence Livermore National Laboratory under Contract W-7405-Eng-48. 


\section{ISO 17025 Accreditation Experience at LLNL}

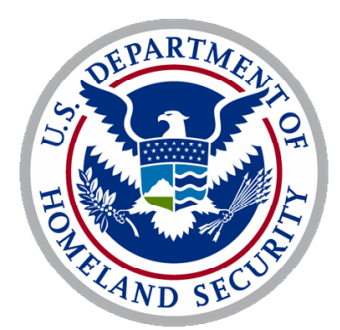

Tuijauna Mitchell-Hall

Lawrence Livermore National Laboratory

2006 DHS Signatures \& Knowledge Base Program Review

September 12-14, 2006

Arlington, VA 


\section{What is accreditation?}

- Laboratory accreditation is defined as formal recognition of an organization's technical competency to perform specific tests.

- LLNL has been accredited by the American Association for Laboratory Accreditation (A2LA).

- LLNL has been ISO 17025 accredited since February 2001. The Nuclear Forensic accreditation was granted in July 2006. 


\section{What does the accreditation mean?}

In effect, an independent, recognized accreditation body, A2LA, attests that LLNL has demonstrated:

- it is competent to perform specific tests, types of tests, calibrations or types of calibrations listed on its Scope(s) of Accreditation;

- it's management system addresses and conforms to all elements of ISO/IEC 17025, is documented per ISO/IEC 17025 , and is fully operational;

— it is operating in accordance with its management system; and;

— it conforms to any additional requirements of A2LA or specific fields or programs necessary to meet particular user needs. 


\section{LLNL Accreditation Preparation (Summary)}

- Purchase a copy of ISO 17025

- Identify tests for accreditation

- Identify individual in charge of the quality system (strong top management support)

- Discuss the relevant components of the accreditation process with applicable individuals.

- Document the policies and procedures in a quality manual and related documentation

- Perform an internal audit or management review to ensure all ISO 17025 requirements are met. Resolve any issues.

- Complete application for accreditation 
1. LLNL obtained an official copy of ISO 17025 and confirms this to A2LA by completing and faxing the ISO 17025 Fax Confirmation Form to A2LA.

2. A2LA provided LLNL with an electronic or hard copy version of the ISO/IEC 17025:2005 Assessor Checklist to perform a self-assessment to verify compliance with all requirements. ( $\sim 60$ pages)

3. LLNL completed and returned the full application for accreditation with payment and all required supporting documentation (e.g. organization chart, quality manual, proficiency test plan, deficiency reports (where applicable), completed ISO 17025:2005 checklist, equipment list, etc.) 


\section{LLNL Accreditation Process (Con't)}

4. A2LA reviewed the application documents and an appropriate assessor(s) is assigned, with laboratory concurrence.

5. The assessor contacted LLNL to discuss the scheduling of the on-site assessment and requested any additional quality documentation that may be needed.

6. The assessment was performed and included: entry briefing; records, sample handling; interviews with scientists; demonstrations of tests/ calibrations; examination of equipment and calibration records; review of quality documentation; written report of assessor's findings; and exit briefing. 


\section{LLNL Accreditation Process (Con't)}

7. LLNL responded to any deficiencies with a written corrective action response.

8. The corrective action was reviewed by the A2LA staff and, once complete, was forwarded to the Accreditation Council for a vote.

9. Accreditation was granted when affirmative votes from the Accreditation Council was received, all concerns were resolved, and all fees were paid in full. 


\section{LLNL ISO 17025 Accreditation (Cert 1914.02)}
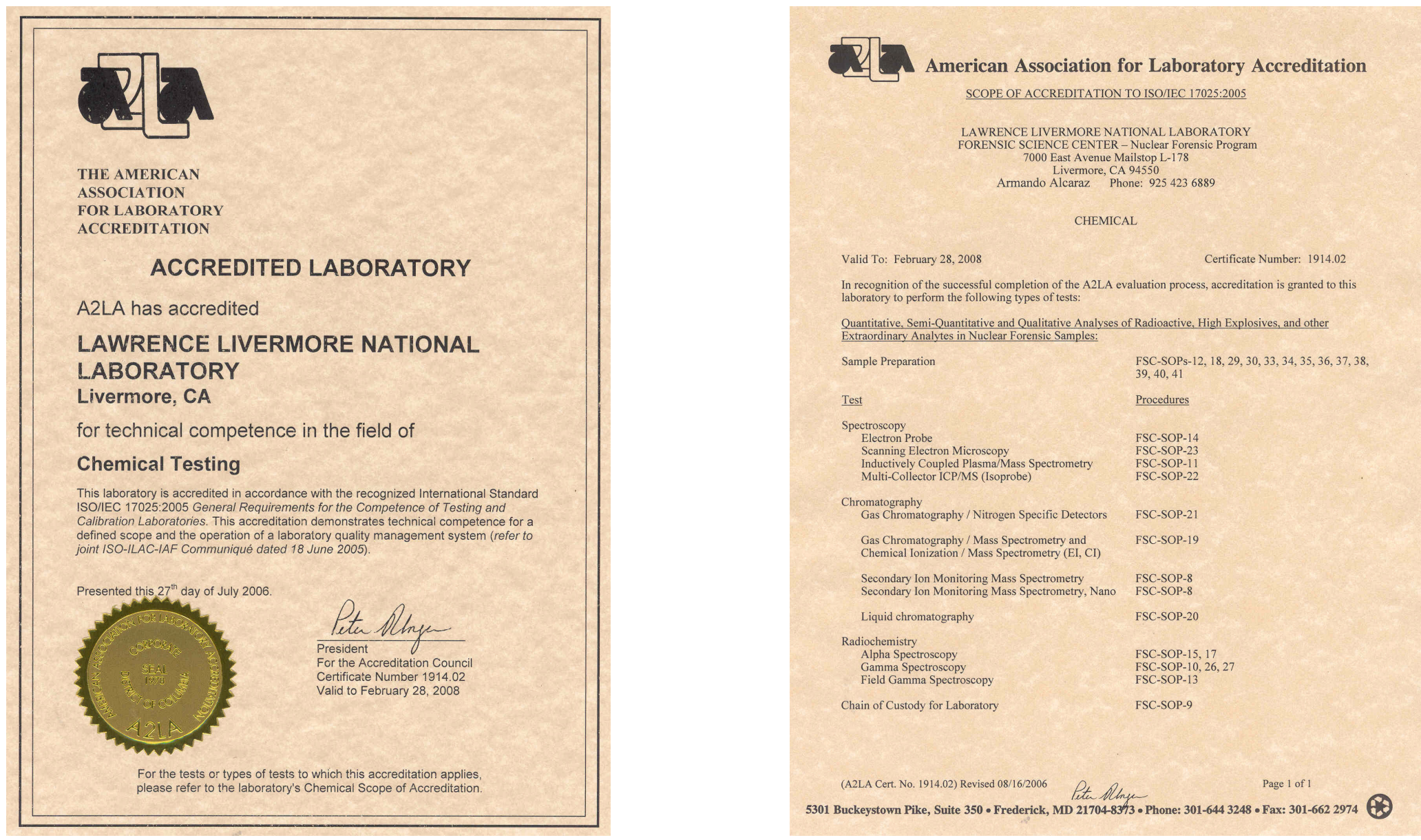
LLNL Accreditation Scope for Radioactive, High Explosive and Other Analytes in Nuclear Forensic Samples

Quantitative, Semi-Quantitative and Qualitative Analysis

- Spectroscopy

- Electron Probe

- Scanning Electron Microscopy

- Inductively Coupled Plasma/Mass Spectrometry

- Multi-Collector ICP/MS (Isoprobe)

- Secondary Ion Monitoring Mass Spectrometry

- Secondary Ion Monitoring Mass Spectrometry, Nano
- Chromatography

- Gas

Chromatography/Nitrogen Specific Detector

- Gas Chromatography/Mass Spectrometry and Chemical Ionization/Mass Spectrometry $(\mathrm{El}, \mathrm{Cl})$

- Liquid Chromatography

- Radiochemistry

- Alpha Spectroscopy

- Gamma Spectroscopy

- Field Gamma Spectroscopy 


\section{Future Accreditation Tests Additions}

\section{For High Explosives Detection*}

Nuclear Magnetic Resonance

Capillary Electrophoresis

Liquid Chromatography/ Electrospray Ionization Mass Spectrometry

Liquid Chromatography/ Atmospheric Pressure Chemical Ionization/Mass Spectrometry

* Planned for addition in FY07. 


\section{Adding Tests to Existing Scope}

To expand tests on an existing scope of accreditation, LLNL will:

- Submit the request to A2LA Headquarters in writing.

- Each request is handled on a case-by-case basis.

- Unless the previous assessor can verify the competence of the laboratory to perform the additional tests, another site visit by A2LA assessor will be required.

- The assessor can recommend a scope addition without a site visit

- extensive review of supporting documentation required

- LLNL may be invoiced if the review greater than an hour.

- If the additional tests require a new technology, another assessment is definitely required. 


\section{How much did it cost?}

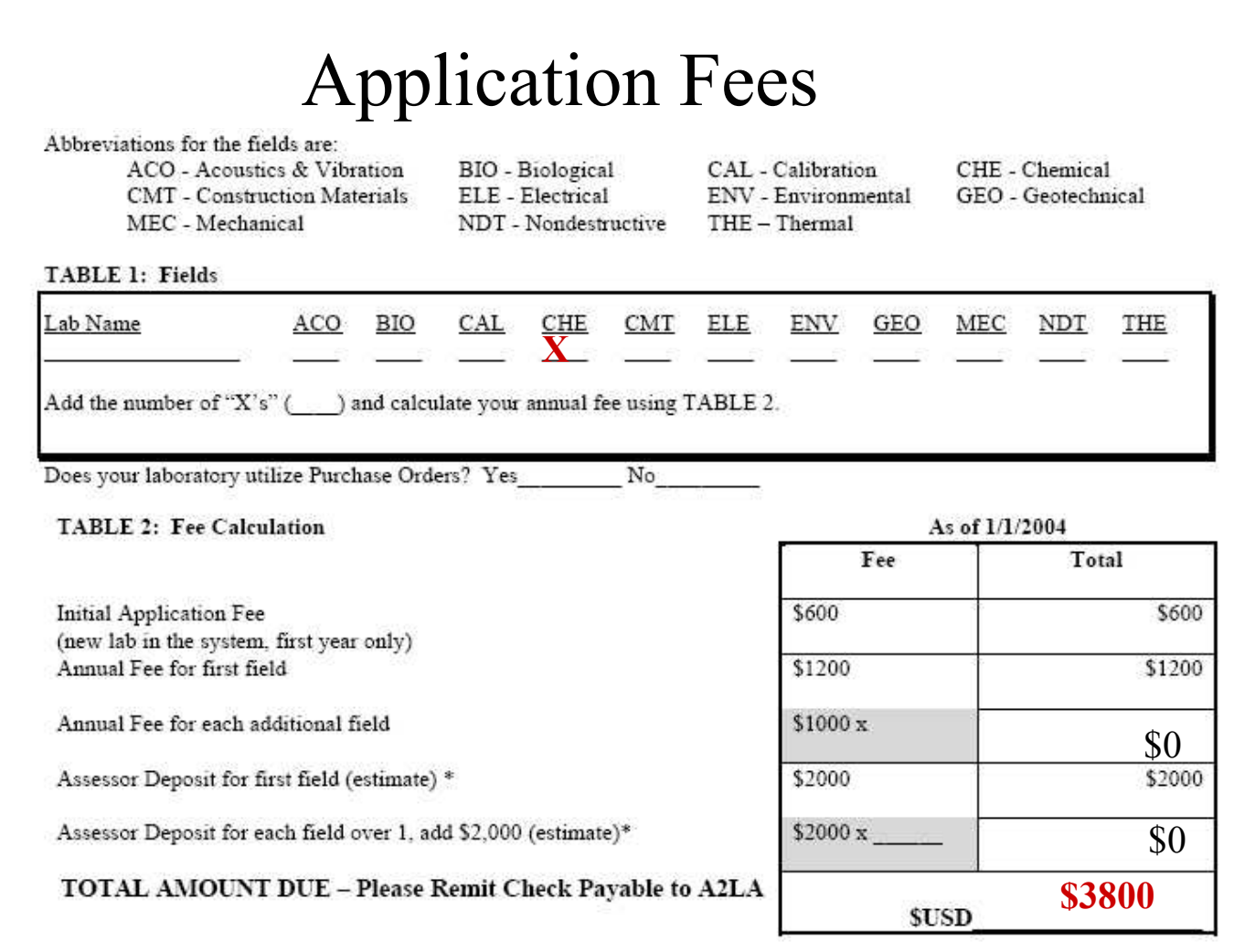

(*NoTE: Lab will be billed or refunded the difference between actual cost and this deposit. Accreditation will not be granted until all fees are paid.

For A2LA Office use Only:

MASTER CODE:

ASSESSMENT NO

CERT NO:

\section{IMPORTANT!!}

The total costs for the accreditation varies depending on the facility's readiness.

Most of the costs are labor costs. 
Lessons Learned

- Buy-In

- Cost Estimates

- Proficiency Tests

- Essential Personnel Identification 


\section{Resources}

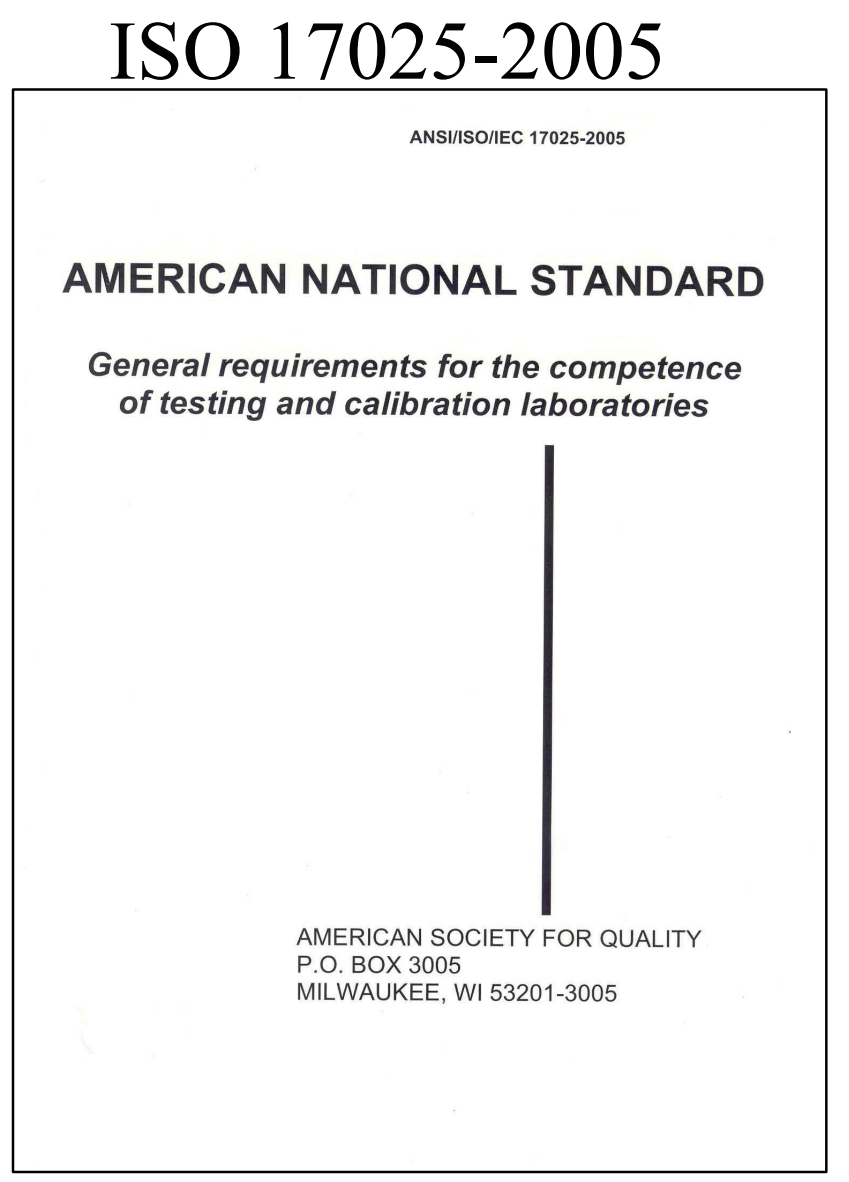

\section{Hard Copy Version American Society for Quality (ASQ) - \\ Quality Press Bookstore}

Web site: www.qualitypress.asq.org

Phone: (414) 2728575 or (800) 2481946

Global Engineering Documents

Web site: www.global.ihs.com

Phone: (303) 3977956 or (800) 8547179

Electronic Version American National Standards Institute (ANSI) Electronic Standards Store (ESS)

Web site: www.ansi.org

Phone: (212) 6424900

- American Association for Laboratory Accreditation http://www.a2la.org/ 